\title{
Torsion of the vermiform appendix: A rare intraoperative finding
}

\author{
Muhammad Yaman Adi, Mohammad Bader, Ingo Jester
}

\begin{abstract}
Introduction: Torsion of the vermiform appendix is a rare intraoperative diagnosis. The clinical presentation is identical to that of acute appendicitis, with preoperative investigations playing a minimal role. The aetiology of the torsion is unclear, though it has been associated with fecoliths, lipomas and mucoceles of the appendix. Case Report: This case report describes a rare presentation of a four-year-old boy with a history and examination classical of acute appendicitis. Intraoperatively, a torsion of the vermiform appendix was found. The clinical presentation and operative intervention are reviewed. Conclusion: Torsion of the vermiform appendix is a rare cause of acute abdominal pain, mimicking acute appendicitis in presentation. Clinicians need to be aware of this intraoperative diagnosis and be able to manage it in the theatre.
\end{abstract}

Keywords: Torsion, Vermiform appendix, Appendicitis, Pediatric

$* * * * * * * * *$

Muhammad Yaman Adi $^{1}$, Mohammad Bader ${ }^{2}$, Ingo Jester ${ }^{3}$ Affiliations: ${ }^{1}$ Senior House Officer, Department of Paediatric Surgery, Birmingham Children's Hospital, Birmingham, United Kingdom; '2Surgical Registrar, Department of Paediatric Surgery, Birmingham Children's Hospital, Birmingham, United Kingdom; ${ }^{3}$ Consultant Paediatric Surgeon, Department of Paediatric Surgery, Birmingham Children's Hospital, Birmingham, United Kingdom.

Corresponding Author: Muhammad Yaman Adi, Birmingham Children's Hospital, Steelhouse Lane, Birmingham, B4 6NH, United Kingdom; Ph: 00447979152593; Email: yamanadi@ msn.com

Received: 12 November 2013

Accepted: 18 Decemmber 2013

Published: 01 April 2014

\section{How to cite this article}

Adi MY, Bader M, Jester I. Torsion of the vermiform appendix: A rare intraoperative finding. International Journal of Case Reports and Images 2014;5(4):299301.

doi:10.5348/ijcri-201461-CR-10372

\section{INTRODUCTION}

Torsion of the vermiform appendix is a rare intraoperative diagnosis. It was first reported in 1918, which was clinically identical in presentation to acute appendicitis [1]. It has been reported 30 times in the last century, half of which were in pediatric patients [2]. The aetiology of the torsion is unclear. Herein, we present a four-year-old boy with acute appendicitis and diagnosed as appendicular torsion.

\section{CASE REPORT}

A four-year-old boy was presented with a three-day history of central abdominal pain and vomiting. Pain was localized to the right iliac fossa. On examination, he was pyrexial. He had a tender abdomen with rebound tenderness in the right iliac fossa. He had a past medical history of adenotonsillectomy and grommet insertions.

No hematological or radiological investigations were required. Clinical examination was suggestive of acute appendicitis. Therefore, he was taken to operation theatre for a laparoscopic appendicectomy on the same day.

At the time of operation, he was discovered to have 720 degrees torsion of the vermiform appendix (Figure 1) with ischemic changes in the distal half. A thrombosed vessel was visualized. A perforation was not present. The appendix had adhered to the inner inguinal opening, however a patent orifice was not seen. The appendix 
was then peeled off this area and three endoloops were applied and appendicectomy was performed. He made an uneventful recovery and was discharged the following day. His histopathology was consistent with hemorrhagic infarction of the appendix.

\section{Histopathology}

Macroscopic: The appendix measured $7 \times 1 \times 1 \mathrm{~cm}$ with a congested surface and hemorrhagic attached fat $3 \times 2 \mathrm{~cm}$. On the cut surface the appendix wall was brown and had hemorrhagic luminal contents.

Microscopic: This confirmed severe acute congestion of the appendiceal wall associated with extensive mucosal, subserosal as well as mesoappendiceal hemorrhage. The mucosa was completely necrotic and focally the necrosis extended into the muscularis propria. Acute serosal inflammation was also present.

Diagnostic summary: Hemorrhagic infarction of the appendix.

\section{DISCUSSION}

Even though acute appendicitis is one of the most common surgical emergencies, torsion of the vermiform appendix, which mimics acute appendicitis, is a rare phenomenon. It is unclear how the torsion develops though several aetiologies have been reported. Some have described it as a primary event due to the appendix being of a longer length, having poor fixation and narrow mesentery. Others have reported cases as a secondary event due to irregular peristaltic movements of the appendix [1], inflammation of the distal appendix [3], or presence of fecoliths, lipomas and mucoceles of the appendix [4-6]. Mostly, the appendix torsion is in a counterclockwise direction (as in this case) [6].

It is difficult to describe the exact cause of the torsion in this case. We theorized two questions: Was the torsion a primary event that caused tip inflammation, which then led it to adhere to the anterior abdominal wall? Or did the inflammation of the appendix cause the tip to adhere to the abdominal wall, which then led to the torsion

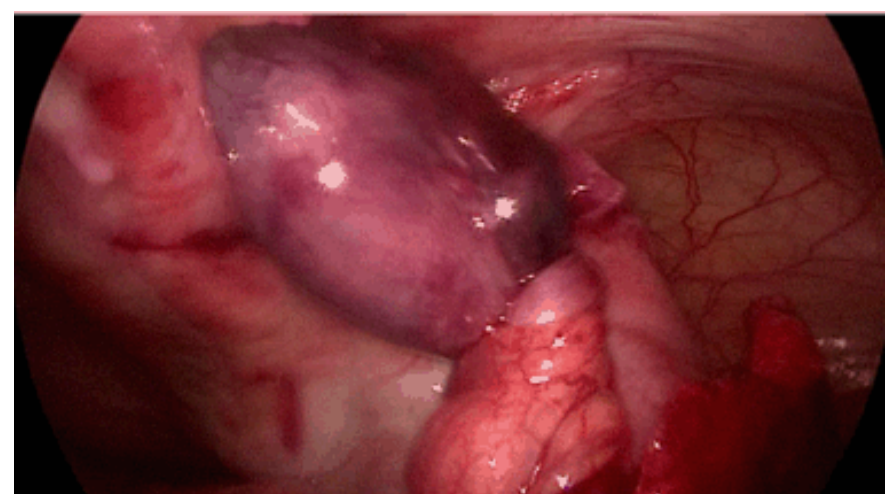

Figure 1: Intraoperative laparoscopic photograph: Torsion of the vermiform appendix (720 degrees). by secondary means such as poor fixation or bowel peristalsis? Other secondary factors, such as fecoliths, lipomas or mucoceles, were not present in this case.

The position of the appendix in these cases is commonly described as lying free or pelvic [7]. However, the case reported revealed an appendix that had adhered to the anterior abdominal wall.

Imaging does not play major role in these cases. One report described how an ultrasound scan performed twice showed a distended bowel loop on both the occasions [8], but still underwent an operation for diagnostic and therapeutic measures. This patient had the same outcome as the case reported above, though investigations were not performed in our case.

\section{CONCLUSION}

Torsion of the vermiform appendix is a rare finding in patients presenting as an acute appendicitis. The diagnosis remains an intraoperative one, with preoperative investigations playing a minimal role. The torsion can be caused by a primary or secondary event. Nonetheless, they will have an appendectomy performed, and therefore the operating surgeon needs to be aware of this intraoperative finding and how to manage it.

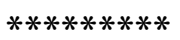

\section{Author Contributions}

Muhammad Yaman Adi - Acquisition of data, Analysis and interpretation of data, Drafting the article, Critical revision of the article, Final approval of the version to be published

Mohammad Bader - Conception and design, Analysis and interpretation of data, Drafting the article, Critical revision of the article, Final approval of the version to be published

Ingo Jester - Conception and design, Analysis and interpretation of data, Critical revision of the article, Final approval of the version to be published

\section{Guarantor}

The corresponding author is the guarantor of submission.

\section{Conflict of Interest}

Authors declare no conflict of interest.

\section{Copyright}

(C) Muhammad Yaman Adi et al. 2014; This article is distributed under the terms of Creative Commons attribution 3.0 License which permits unrestricted use, distribution and reproduction in any means provided the original authors and original publisher are properly credited. (Please see www.ijcasereportsandimages.com/ copyright-policy.php for more information.) 


\section{REFERENCES}

1. Payne JE. A case of torsion of the appendix. Br J Surg 1918;6:327.

2. Bestman TJ, van Cleemput M, Detournay G. Torsion of the vermiform appendix: A case report. Acta Chir Belg 2006;106(2):228-9.

3. Bevers EC. Torsion of the appendix. Lancet 1920:597.

4. Killam AR. An unusual cause of appendicitis: Torsion produced by a mesoappendiceal lipoma. Am Surg 1969;35(9):648-9.

5. Dicknson DR, Jennings WK. Mucocele of the appendix complicated by torsion and gangrene. Calif Med 1953;79(4):317-8.
6. Gopal K, Kumar S, Grewal H. Torsion of the vermiform appendix. J Pediatr Surg 2005;40(2):446-7.

7. Val-Bernal JF, Gonzalez-Vela C, Garijo MF. Primary acute torsion of the vermiform appendix. Pediatr Pathol Lab Med 1996;16(4):655-1.

8. Uroz-Tristan J, García-Urgelles X, Poenaru D, AvilaSuarez R, Valenciano-Fuentes B. Torsion of vermiform appendix: Value of ultrasonographic findings. Eur J Pediatr Surg 1998;8(6):376-7.
Access full text article on other devices

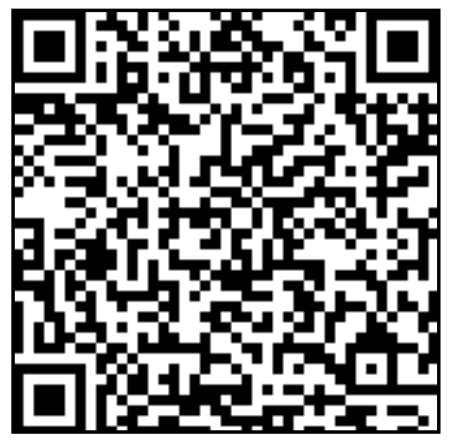

Access PDF of article on other devices

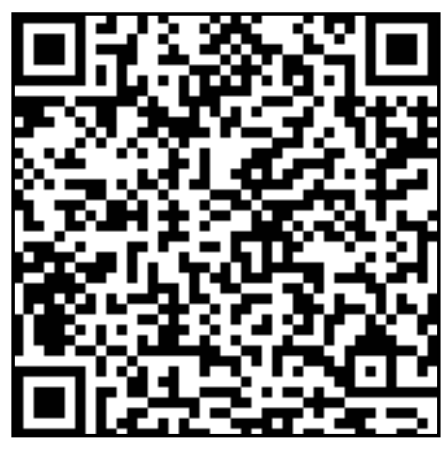

